DOI: $10.14451 / 1.185 .20$

\title{
ЭВОЛЮЦИЯ ТЕОРИИ СОБСТВЕННОСТИ: ХОЛИЗМ VS ИНДИВИДУАЛИЗМ
}

\author{
(C) 2020 Карамова Ольга Владимировна
}

доктор экономических наук, доцент, профессор департамента экономической теории Финансовый университет при Правительстве Российской Федерации, Россия, Москва

Email: okaramova@fa.ru

ORCID: 0000-0003-3713-7994

Статья посвящена исследованию эволюции теории собственности в рамках основных научных направлений и школ. Автор рассмотрел проблему дихотомии методологического индивидуализма и методологического холизма в теории собственности. В статье показано как противостояние между индивидуализмом и холизмом сменяется на консенсусные и комплементарные трактовки отношений собственности.

Ключевые слова: теория собственности, методологический индивидуализм, методологический холизм, теория прав собственности, неомарксизм, неоинституционализм.

В теории собственности сконцентрированы самые важные и практически значимые экономические интересы отдельных людей, фирм и общества. Это объясняет, почему экономическая категория собственности занимает ведущее место в научных исследованиях во все периоды развития всех научных направлений экономической науки.

Проблемы, возникающие в отношениях собственности всегда были очень острыми и значимыми, однако в экономической науке отсутствует единое определение и подход в понимании этой экономической категории.

Для лучшего объяснения существующих подходов к теории собственности следует остановиться на эволюции теории.

Теория собственности прошла ряд этапов в своем развитии, которые представлены в таблице «Морфологический анализ эволюции теории собственности».

На современном этапе развития теории собственности в методологическом плане сформировалась дихотомия методологического индивидуализма и методологического холизма, которая является системной проблемой и составляет теоретическое ядро экономической теории. Индивидуализм и холизм вступают друг с другом в диалектическое противоречие, которое является базисным и фундаментальным [9].

В рамках процесса формирования теории собственности, методологический индивидуализм и методологический холизм используются для анализа экономических явлений, изучаемых в двух аспектах: либо как деятельность самостоятельных экономических субъектов, либо как процессы, развивающиеся на уровне целой системы, в которую вовлекаются индивиды.

Методология холизма и индивидуализма прослеживается на всех этапах развития теории собственности. В XIX-XX веках теории собственности, основанные на разных методологических подходах - индивидуализме и холизме, противостояли друг другу и находились в жесткой конфронтации. Определение собственности с позиций методологического холизма характерно для марксизма, немецкой исторической школы, традиционного институционализма, эволюционизма и современного неомарксизма. Методологический холизм означает, что экономические системы не тождественны сумме действий отдельных субъектов и их экономическим интересам. Экономические закономерности, действующие на уровне систем, не редуцируются до закономерностей поведения отдельных субъектов. Холистический подход акцентирует внимание на воспроизводственных отношениях в хозяйственной системе и общих социальноэкономических условиях.

Собственность рассматривается не как отношение человек-вещь, в как отношения человек-

\footnotetext{
* Статья написана в рамках фундаментальной научно - исследовательской работы (Регистрационный № НИОКР ВТК-ГЗ-ФИ-16-19) по теме: «Развитие теории отношений собственности в современном обществе» выполняемой по заказу Правительства Российской Федерации в ФГОБУ ВО «Финансовый университет при Правительстве Российской Федерации».
} 
Таблица 1. Морфологический анализ эволюции теории собственности

\begin{tabular}{|c|c|c|c|}
\hline $\begin{array}{c}\text { Период развития } \\
\text { теории собственности }\end{array}$ & $\begin{array}{c}\text { Общая характеристика } \\
\text { теории собственности }\end{array}$ & $\begin{array}{c}\text { Методологические } \\
\text { основы теории } \\
\text { собственности }\end{array}$ & $\begin{array}{c}\text { Эволюция трактовок } \\
\text { теории собственности }\end{array}$ \\
\hline \multicolumn{4}{|c|}{ Древняя Греция и Древний Рим } \\
\hline IV в. до н.э. - V в. & $\begin{array}{l}\text { Платон - общая соб- } \\
\text { ственность в идеальном } \\
\text { государстве, } \\
\text { Аристотель - частная } \\
\text { собственность, как усло- } \\
\text { вие и предпосылка хозяй- } \\
\text { ствования. Римское право } \\
\text { определило элементы } \\
\text { собственности. }\end{array}$ & $\begin{array}{l}\text { Зарождение методов } \\
\text { научного познания, фор- } \\
\text { мальной логики (Аристо- } \\
\text { теля), метода анализа и } \\
\text { синтеза. Выделение эко- } \\
\text { номии и хрематистики. }\end{array}$ & $\begin{array}{l}\text { Римское право определи- } \\
\text { ло элементы собственно- } \\
\text { сти, как право владения, } \\
\text { пользования и распоря- } \\
\text { жения }\end{array}$ \\
\hline \multicolumn{4}{|c|}{ Теория естественного права } \\
\hline $\begin{array}{l}\text { Новое время в эпоху } \\
\text { буржуазных революций } \\
\text { XVII-XVIII вв. }\end{array}$ & $\begin{array}{l}\text { Принципы и институ- } \\
\text { ты феодального права } \\
\text { необходимо заменить } \\
\text { на нормы гражданского } \\
\text { права. }\end{array}$ & \begin{tabular}{|l} 
Деление права на пози- \\
тивное и естественное. \\
Право определяется как \\
абстрактно-нравственная \\
ценность, определяющая \\
свободу, равенство людей, \\
право частной собствен- \\
ности, свободу вероиспо- \\
ведания и мысли и др.
\end{tabular} & $\begin{array}{l}\text { Народ являлся сувереном } \\
\text { права, обладателем прав } \\
\text { личности. Государь обя- } \\
\text { зан был править согласно } \\
\text { установленным законам, } \\
\text { которые были провозгла- } \\
\text { шены народом и извест- } \\
\text { ны народу. Народ имел } \\
\text { право лишить правителя } \\
\text { его власти, если он не } \\
\text { выполнял своих обяза- } \\
\text { тельств. }\end{array}$ \\
\hline \multicolumn{4}{|c|}{ Классическая политическая экономия } \\
\hline XVIII-XIX вв. & $\begin{array}{l}\text { Частная собственность } \\
\text { рассматривалась как } \\
\text { основа свободы «эконо- } \\
\text { мического человека», } \\
\text { предпринимательства и } \\
\text { рыночной экономики. }\end{array}$ & $\begin{array}{l}\text { В основе изучения } \\
\text { частной собственности } \\
\text { лежали методологиче- } \\
\text { ский индивидуализм и } \\
\text { рационализм, причинно- } \\
\text { следственный метод, } \\
\text { гипотетико-дедуктивный } \\
\text { метод. }\end{array}$ & $\begin{array}{l}\text { Где есть большая соб- } \\
\text { ственность, там есть } \\
\text { большое неравенство. } \\
\text { Частная собственность } \\
\text { есть основа свободы } \\
\text { предпринимателя в ры- } \\
\text { ночной экономике. }\end{array}$ \\
\hline \multicolumn{4}{|l|}{ Социалисты-утописты } \\
\hline XIX век & $\begin{array}{l}\text { Выражали интересы } \\
\text { угнетенных трудящихся. } \\
\text { В противовес частной } \\
\text { собственности разраба- } \\
\text { тывали идеи и проводили } \\
\text { эксперименты по созда- } \\
\text { нию новой коллективной } \\
\text { и трудовой форм соб- } \\
\text { ственности. }\end{array}$ & $\begin{array}{l}\text { Эмпирический, описа- } \\
\text { тельный метод. Норма- } \\
\text { тивный подход. }\end{array}$ & $\begin{array}{l}\text { Собственность - это кра- } \\
\text { жа (Прудон) }\end{array}$ \\
\hline \multicolumn{4}{|l|}{ Марксизм } \\
\hline XIX-XX века & $\begin{array}{l}\text { Собственность - это эко- } \\
\text { номическое отношения } \\
\text { между людьми, а не отно- } \\
\text { шение человека к вещи. } \\
\text { На основе экономическо- } \\
\text { го содержания отноше- } \\
\text { ний собственности были } \\
\text { сформулированы базовые } \\
\text { принципы общенарод- } \\
\text { ной социалистической } \\
\text { собственности. }\end{array}$ & $\begin{array}{l}\text { Методологический } \\
\text { холизм. Диалектический } \\
\text { материализм. Истори- } \\
\text { ческий материализм. } \\
\text { Отношения собственно- } \\
\text { сти исторически сменя- } \\
\text { ются, определяют эконо- } \\
\text { мическую формацию и } \\
\text { соответствуют ей. }\end{array}$ & $\begin{array}{l}\text { Собственность - это } \\
\text { базисное, объективное } \\
\text { производственное отно- } \\
\text { шение, детерминирую- } \\
\text { щее способ производства. } \\
\text { Отношения собственно- } \\
\text { сти определяют способ } \\
\text { присвоения обществен- } \\
\text { ного богатства и его } \\
\text { отчуждения от работника. } \\
\text { Исторически неизбежна } \\
\text { революционная смена } \\
\text { форм собственности и } \\
\text { ликвидация частной } \\
\text { капиталистической соб- } \\
\text { ственности. }\end{array}$ \\
\hline
\end{tabular}




\begin{tabular}{|c|c|c|c|}
\hline \multicolumn{4}{|c|}{ Неоклассическая научная школа } \\
\hline XIX-XX вв. & $\begin{array}{l}\text { В основу отношений } \\
\text { собственности ставится } \\
\text { принцип редкости ресур- } \\
\text { сов и их относительной } \\
\text { ограниченности по отно- } \\
\text { шению к потребностям } \\
\text { людей. }\end{array}$ & $\begin{array}{l}\text { Методологический инди- } \\
\text { видуализм. Поведенче- } \\
\text { ский подход к изучению } \\
\text { отношений собственно- } \\
\text { сти. Отношения собствен- } \\
\text { ности связаны с редко- } \\
\text { стью ресурсов. }\end{array}$ & $\begin{array}{l}\text { Частная собственность } \\
\text { есть основа свободы } \\
\text { предпринимателя в ры- } \\
\text { ночной экономике. }\end{array}$ \\
\hline \multicolumn{4}{|c|}{ Традиционный институционализм } \\
\hline $\begin{array}{l}\text { Начало и середина } \\
\text { XX века }\end{array}$ & $\begin{array}{l}\text { Изучение крупной капи- } \\
\text { талистической частной } \\
\text { собственности. Идеи } \\
\text { правового урегулирова- } \\
\text { ния конфликтов между } \\
\text { трудом и капиталом, про- } \\
\text { грамма «политического } \\
\text { коллективного договора». }\end{array}$ & \begin{tabular}{|l} 
Методологический хо- \\
лизм. Анализ институтов. \\
Изучение неформальных \\
и формальных институ- \\
тов, отдается приоритет \\
первым. Разработка \\
концепции собственно- \\
сти, связанной с поиском \\
социального консенсуса.
\end{tabular} & $\begin{array}{l}\text { Крупная капиталистиче- } \\
\text { ская частная собствен- } \\
\text { ность - это основание } \\
\text { для «хищничества и } \\
\text { паразитизма» со стороны } \\
\text { праздного класса. }\end{array}$ \\
\hline \multicolumn{4}{|c|}{ Неоинституционализм } \\
\hline XX-XXI вв. & $\begin{array}{l}\text { Теория прав собствен- } \\
\text { ности. Задача отразить } \\
\text { экономическую ответ- } \\
\text { ственность за результаты } \\
\text { использования собствен- } \\
\text { ности, которая не улавли- } \\
\text { валась системой рынка и } \\
\text { разработать соответству- } \\
\text { ющие компенсационные } \\
\text { механизмы. }\end{array}$ & $\begin{array}{l}\text { Методологический } \\
\text { индивидуализм. Инсти- } \\
\text { туциональный подход. } \\
\text { Собственность рассма- } \\
\text { тривается как пучок } \\
\text { прав собственности. } \\
\text { Права собственности это } \\
\text { определенные «правила } \\
\text { игры», санкционирован- } \\
\text { ные обществом. }\end{array}$ & $\begin{array}{l}\text { Права собственности - } \\
\text { это права контроля по } \\
\text { использованию ресурсов } \\
\text { и распределению затрат и } \\
\text { выгод. Права собственно- } \\
\text { сти рассматриваются как } \\
\text { правила игры. Размыва- } \\
\text { ние и спецификация прав } \\
\text { собственности. }\end{array}$ \\
\hline \multicolumn{4}{|l|}{ Неомарксизм } \\
\hline XX-XXI вв. & $\begin{array}{l}\text { Собственность является } \\
\text { экономическим отноше- } \\
\text { нием между людьми. }\end{array}$ & $\begin{array}{l}\text { Методологический } \\
\text { холизм. Диалектический } \\
\text { материализм. Историче- } \\
\text { ский материализм. }\end{array}$ & $\begin{array}{l}\text { Отношения собствен- } \\
\text { ности носят классовый } \\
\text { характер. Капиталисти- } \\
\text { ческая частная собствен- } \\
\text { ность является эксплуата- } \\
\text { торской. }\end{array}$ \\
\hline
\end{tabular}

Источник: составлена автором.

человек, которые возникают по поводу производства, обмена, распределения и потребления благ. Взаимодействие людей в воспроизводственном процессе объясняется разделением труда и кооперацией. Отношения собственности изучаются в аспекте отношений присвоения и отчуждения. Поэтому собственность с методологических позиций холизма следует рассматривать как отношения между экономическими акторами по поводу и присвоения и отчуждения в условиях конкретно-исторической экономической системы.

В работе «Нищета философии» (1847 г.) К. Маркса, выражая свои взгляды на собственность, как системного отношения способа производства, пишет: «В каждую историческую эпоху собственность развивается различно и при совершенно различных общественных отношениях. Поэтому определить буржуазную собственность - это значит не что иное, как дать описание всех общественных отношений буржуазного производства. Стремиться дать определение собственности как независимого отношения, как особой категории, как абстрактной и вечной идеи значит впадать в метафизическую или юридическую иллюзию» [7].

Революционный подход К.Маркса, связанный с необходимостью ликвидировать частную собственность, выражался в его выводе: «Централизация средств производства и обобществление труда достигают такого пункта, когда они становятся несовместимыми с их капиталистической оболочкой. Она взрывается. Бьет час капиталистической частной собственности. Экспроприаторов экспроприируют» [8].

Методология холизма четко прослеживается в высказывании А.В.Бузгалина, что социальнополитическая структур, контролирующая основные права собственности в данной экономической системе, связана «с вопросом о способе 
присвоения общественного богатства и способе его отчуждения от работника». Неомарксисты Бузгалин А. и Колганов А. [2] считают, что для российской экономики характерен процесс интегрирования огосударствленной собственности в предыдущие периоды с собственностью крупных корпораций, функционирующих по образцу собственности, свойственной позднему капитализму. Также прослеживается тенденция воссоздания добуржуазных форм принуждения и зависимости. Эти процессы характерны в определенной степени для всех трансформационных экономик, но в российской экономике получили наибольшее развитие и превратились в господствующие. С точки зрения неомарксистов, в результате указанных процессов создалось некое доминирующее в современной экономике подпространство, характеризующееся превалированием отношений «кланово-корпоративного отчуждения и присвоения».

Определение собственности с позиций методологического индивидуализма сформировалось в классической политической экономии, маржинализме, неоклассике, неоинституционализме [5]. Для индивидуализма в онтологическом аспекте характерно то, что первичным элементом исследования являются отдельные индивиды и их действия, а также отсутствуют надындивидуальные отношения или экономические интересы (экономический атомизм).

Методологический индивидуализма в теории собственности используется в виде аналитического приема, определяющий экономических субъектов собственности рациональными и автономными. Свойства экономической системы на уровне макропроцессов выводятся из отношений частной собственности субъектов, т.е. свойства системы предопределяются свойствами ее отдельных элементов.

В рамках методологического индивидуализма в классической политической экономии сформировался подход к восприятию частной собственности как защите личности индивида.

Неоклассическая парадигма предполагает, что форма собственности имеет мало значения, а частная собственность в большинстве сфер экономики более эффективна по сравнению с государственной собственностью.

Методология индивидуализма, лежащая в основе теории права собственности, приводит к следующему определению собственности, которое сформулировал А.Алчиан: «Собственность на ресурсы и функция их распределения сосредоточены в руках таких неправительственных организаций, как фирмы, домашние хозяйства и рынки. Собственники ресурсов повышают их производительность посредством кооперативной специализации, что вызывает потребность в экономических организациях, облегчающих кооперацию» [1].

С развитием институциональной и неоинституциональной теории во второй половине $\mathrm{XX}$ века и в настоящий период, критическая нетерпимость между методологическим индивидуализмом и методологическим холизмом сменяется на консенсусные и комплементарные трактовки отношений собственности. В отличие от марксистский теории революционной смены форм собственности и ликвидации частной собственности, институционалисты развивают концепцию собственности, связанную с социальным консенсусом.

Разрешение этих вызовов в современной экономике реализовалось в формировании неоинституциональной теории права собственности (economics of property right) в 1960-1970-e гг. В соответствии с основной концепцией неоинституционализма - теорией прав собственности, считается, что в качестве собственности надо рассматривать не только сами ресурсы, а права на собственность в виде пучка прав (11 прав А. Оноре).

Развивая современную теорию собственности, Вольчик В. В. отмечает: «Делается акцент на важности делиберативного процесса во взаимодействии различных научных школ» [3] и не только «в рамках современной институциональной экономической теории» но и шире в аспекте холистической методологии и методологического индивидуализма.

Цифровая экономика создает предпосылки для динамичной трансформации отношений собственности, что находит отражение в теории собственности. Для российской экономической школы характерно изучение отношений собственности в методологии эволюционного институционализма $[6,10]$. Российский экономисты остаются в своем большинстве на позициях методологического холизма, отмечают существенную роль государственной собственности в развитии современных технологий. Звягинцев П.С. пишет: «Несмотря на незначительное количество оставшихся у государства предприятий $(2,2 \%)$, число организаций с государственной 
собственностью, разрабатывавших нанотехнологии, и число разработанных нанотехнологий в 2017 году в Российской Федерации больше числа организаций с частной собственностью и количества разработанных нанотехнологий. Число используемых нанотехнологий организациями с государственной собственностью за 2017 год составило 435 единиц, а число организаций с частной собственностью 428 единиц» [4].

Таким образом, на современном этапе развития теории собственности доминируют две научные школы - неоинституционализм, рассматривающий теорию собственности с позиций методологического индивидуализм; и неомарксизм - основанный на методологическом холизме. В то же время теория собственности в рамках таких научных школ как неоклассика, монетаризм, традиционный институционализм, отходит на второй план.

В экономической науке происходит процесс создания концепта теории собственности, соответствующий потребностям современной цифровой экономики, который включает актуальные аспекты трансформации отношений собственности. К ним относится проблема деперсонификации собственников, изучение поведенческих особенностей при восприятии стимулов частной собственности, решение задачи развития институциональной среды на основе радикального повышения качества институтов государства.

\section{Библиографический список}

1. Алчиан А., Демсеи X, Производство, информационные издержки и экономическая организация // Истоки, М.: Издательский дом ГУ-ВШЭ, 2004, стр. 166-207.

2. Бузгалин А., Колганов А. Российская экономическая система: специфика отношенийсобственности и внутрикорпоративного управления //Журнал «Проблемы теории и практики управления» 2014, № 10. С.8-9.

3. Вольчик B.В. Институциональные подходы к исследованию собственности: возможен ли синтез?// TERRA ECONOMICUS № 2 Tом 12. 2014 C. 22.

4. Звягинцев П. С. Управление государственной собственностью как фактор влияния на инновационное развитие экономики России // Экономические науки. 2019. № 9 (178) C.76-81. DOI: 10.14451/1.178.76.

5. Карамова О.В. Дискурсы методологического индивидуализма и этического холизма в экономической науке // Экономические науки. - 2013. - № 3 (100). - С. 55-58.

6. Ларионов А.В., Коновалова М.Е., Кузьмина О. Ю. Институциональная среда формирования и развития интеллектуального капитала //Экономические науки.2020. № 1 (182). С. 21-24. DOI: 10.14451/1.182.21.

7. Маркс К., Энгельс Ф. Соч.2-е изд. В 50-томах. -М.: Гл. изд-во полит. Литературы, 1955-1974. - Т.2. С. 156.

8. Маркс К. и Энгельс Ф. Соч.2-е изд. В 50-томах. -М.: Гл. изд-во полит. Литературы, 1955-1974. - Т.23. С. $772-73$.

9. Степин В. С. Теоретическое знание. Структура, историческая эволюция.- М.: Прогресс - Традиция, 2003 г.

10. Трубецикая О. В. Институциональные изменения и цифровая экономика // Экономические науки. 2019. № 12 (181) c.74-78. DOI: 10.14451/1.181.74. 